\title{
Recuperación y reevaluación del concepto de derecho krausista en España*
}

\author{
Delia Manzanero ${ }^{1}$ \\ Universidad Rey Juan Carlos de Madrid \\ deliadelos@urjc.es
}

RESUMEN: Este artículo considera la especial determinación de la esencia del Derecho y la metodología jurídica en la obra de un krausista español como fue Francisco Giner, para lo cual, se condensan en unas pocas páginas las fijaciones del concepto de Derecho que el propio Krause y sus discipulos más directos han dado a esta cuestión. En segundo lugar, se sintetizan los lineamientos generales de la doctrina de Krause y las resonancias que obtiene, particularmente entre los krausistas españoles, para, en último término, sentar las bases teóricas que permiten entrar a valorar el desarrollo de esta doctrina dentro del marco general de la Filosofía del Derecho de Giner. Por último, se analizan las discrepancias de Giner en cuestiones sumamente trascendentales con otras definiciones del Derecho dadas por krausistas europeos como el jurista alemán Ahrens, alumbrando así un concepto de derecho que sería el que posteriormente alcanzaría mayor amplitud y desarrollo en España al ser recuperado y reasumido por los krausistas españoles.

\section{PALABRAS ClAVE: España; Alemania; derecho; krausismo; filosofía; Giner.}

* Esta investigación se ha realizado en el marco del proyecto de investigación de la Universidad Pontificia Comillas: «Krause y el krausismo del sexenio democrático» (Proyecto de investigación I+D+i: HAR2016-79448-P, 2016-2019), financiado por el Ministerio de Economía y Competitividad. Asimismo, este estudio se inscribe dentro de una Ayuda Juan de la Cierva - Formación Posdoctoral adscrita a la Universidad Rey Juan Carlos de Madrid, financiada por el Ministerio de Economía y Competitividad (FPDI-2013-17242).

1 ORCID iD: http://orcid.org/0000-0002-6895-1254. 


\section{Recovery and re-evaluation of the Krausist concept of law in Spain}

ABSTRACT: This article considers the special determination of the essence of Law and legal methodology in the work of Spanish Krausist author Francisco Giner. To this end, the features of the concept of Law which Krause and his direct disciples provided on this issue are condensed into a few pages. Secondly, the broad outlines of Krause's doctrine and its resonance, specifically among Spanish Krausists, are synthesised in order, ultimately, to lay the theoretical foundations to assess the development of this doctrine in the general framework of Giner's Philosophy of Law. Finally, Giner's discrepancies on extremely significant issues with other definitions of Law by European Krausists, such as the German jurist Ahrens, are also analysed. This throws light on a concept of law that would later achieve broader scope and development in Spain, when recovered and resumed by Spanish Krausists.

KEY WORDS: Spain; Germany; law; Krausism; philosophy; Giner.

CÓMO CITAR ESTE ARTÍCULO/CITATION: Manzanero, Delia, «Recuperación y reevaluación del concepto de derecho krausista en España», Hispania, 77/257 (Madrid, 2017): 827-855. doi: 103989/hispania.2017.023.

\section{INTRODUCCIÓN}

La recepción española de la filosofía krauseana comienza, como es sobradamente conocido, con el viaje de Julián Sanz de Río (1814-1869) a Alemania en 1843, y sus traducciones al español de la obra del filósofo alemán Karl Christian Friedrich Krause (1781-1832). La colosal bibliografía existente sobre la recepción y difusión españolas de la filosofía jurídica krausista en España, hace del todo irrealizable la vana pretensión de exhaustividad en esta materia; además, el conocimiento que se ha tenido de este periodo de recepción, síntesis y proyección de la literatura krausista no ha permanecido invariable $^{2}$, sino que ha evolucionado y mejorado notablemente gracias al descubrimiento del epistolar de una abundante correspondencia que tanto Sanz del

2 Así ha sido expuesto en algunos trabajos sobre la historiografía del krausismo español: VÁZQUEZ-ROMERO, 1999, vol. 16: 2-14. Es importante destacar que se produce una nueva generación de estudios a partir de los trabajos reveladores de MENÉNDEZ UREÑA, 44 (Madrid, 1988): 25-48 y de MENÉNDEZ UREÑA, FERNÁNDEZ y SEIDEL (1992), en virtud de los cuales se da comienzo a una etapa de recuperación del fenómeno krausista en la historiografía española y alemana que arroja nueva luz a las investigaciones y ofrece una aproximación más certera de la filosofía krauseana para el público hispano. También la monumental y muy bien documentada biografía intelectual del filósofo alemán (MENÉNDEZ UREÑA, 1991), representa un estudio de la máxima relevancia para el krausismo, que permite comprenderlo a partir de sus orígenes alemanes y en enmarcarlo dentro del fenómeno más amplio del krausismo europeo. ÁLVAREZ LÁZARO y MENÉNDEZ UREÑA, 1999. 
Río como Francisco Giner de los Ríos intercambiaban con los krausistas alemanes $^{3}$. En ella se da a conocer la patente existencia de una intensa interrelación de mutuo aprecio intelectual entre los miembros de los grupos español y alemán, donde Francisco Giner «pasó inmediatamente a ser tratado por ellos como la cabeza del grupo krausista español» ${ }^{4}$. En tales fuentes documentales se muestra claramente cómo, si bien el influjo de Krause en la mayoría de los españoles krausistas fue efectuado principalmente a través de sus discípulos, no debe caerse en el tópico menéndez-pelayista según el cual Krause fue desconocido entre sus compatriotas y entre los krausistas españoles 5 .

Por esta razón, determinar hasta agotar cuáles fueron los pensadores que influyeron en la formación de la concepción del Derecho krausista en España durante la segunda mitad del siglo XIX y los albores del siglo XX, y analizar el impacto que tuvieron las ideas e ideales propalados por Krause en los intelectuales y políticos españoles en tan limitado espacio sería un empeño vano; no así determinar y analizar el concepto del derecho del filósofo alemán Krause y su influjo sobre los krausistas españoles, conocidos también como los «campeones de la regeneración científica de España» ${ }^{6}$, por su importante proyecto de renovación pedagógica y social krauso-institucionista durante la Edad de Plata española (1868-1936).

En particular, centraremos nuestro análisis en el influjo que la filosofía jurídica krauseana tuvo en la obra de una de las figuras más sobresalientes del krausismo español, Francisco Giner de los Ríos (1839-1915); un influjo que, como se ha indicado, fue efectuado principalmente a través de los principales discípulos de Krause: en Bruselas, con Ahrens y Tiberghien, en Heidelberg con Röder y Leonhardi.

Ciertamente, la difusión internacional que alcanzaron las ideas krausistas, concretamente, en el ámbito de la filosofía jurídica y política, se aprecia sobre todo en Francia con la filosofía jurídica de Heinrich Ahrens (1808-1874), uno de los más importantes propagandistas de las doctrinas de Krause, que tuvo además una de las recepciones más prósperas y fecundas entre los juristas krausistas españoles. De este autor destacamos su Enciclopedia Jurídica, un trabajo magistral de obligada referencia, del que se han hecho infinidad de traducciones y que, siendo considerada obra clásica, fue usada como manual en todas las escuelas de Derecho europeas y americanas y traducida por krausistas españoles ${ }^{7}$. Su influencia queda demostrada por el eco que jurisconsultos y filósofos españoles se hicieron de esta obra, siendo ampliamente debatida por los juristas

\footnotetext{
3 MENÉNDEZ UREÑA y VÁZQUEZ-ROMERO, 2003. MENÉNDEZ UREÑA, 1993.

4 MENÉNDEZ UREÑA, 1998: 89-99.

5 MENÉNDEZ PELAYO, 1978: 955.

6 COSTA, 1982: 260.

7 AHRENS, 1878-1880.
} 
krausistas españoles. Entre ellos, destaca la obra de comentario llevada a cabo por Francisco Giner, Gumersindo de Azcárate y Augusto G. Linares, cuyas revisiones a la obra de Ahrens fueron editadas y ulteriormente publicadas en un monográfico ${ }^{8}$, y cuyo su estudio consideramos del todo necesario para comprender la recepción de concepto de derecho krausista en España.

\section{EL CONCEPTO DE DERECHO DE K. C. F. KRAUSE}

Como se ha expuesto anteriormente, las bases del pensamiento jurídico de Giner se hallan en el filósofo alemán Karl Christian Friedrich Krause, cuyo método y concepto universal del Derecho pasó apenas sin variaciones a sus discípulos.

La concepción jurídica del filósofo de Eisenberg se expone de modo magistral en su Ideal de la Humanidad para la vida (Urbild der Menschheit, 1811). Su concepto del Derecho se precia de tomar el fondo de verdad que hay en teorías ya parcialmente caducas o periclitadas, para exponerlas de manera crítica, por lo que, si atendemos a la opinión de Heinrich Ahrens de que «cuanto más complejo es un concepto del Derecho, sirve tanto mejor para revelar en las doctrinas que lo precedieron la parte de verdad que contienen ${ }^{9}$, ciertamente, encontraremos en la filosofía del derecho de Krause una interesante muestra de ello. De ahí, por ejemplo, que se apoye por ejemplo en el concepto platónico de la justicia interna al que debe ajustarse, en su sentir, el orden exterior del Estado; así como en la concepción cristiana que supo poner la personalidad humana sobre la existencia temporal del Estado, si bien Krause criticará de ambos el desconocer la libertad y autonomía de la persona.

Otro precursor que influyó en la concepción del carácter ético del pensamiento jurídico de Krause fue Leibniz. Así lo expresa Fernando de los Ríos, quien recoge las tres formas fundamentales de justicia que Aristóteles había dado a la tradición occidental del Derecho: la conmutativa, la distributiva, pero sobre todo la justicia general o universal que tiene que ver con esa ordenación al bien común que habría pasado invariablemente de Leibniz a Krause:

El derecho natural comporta tres momentos: Jus strictum o justicia conmutativa, que los romanos llamaron neminen lædere; Aquitas o charitas, justicia distributiva, suum cuique tribure y la Pietas o Probitas, momento de la justicia universal,

8 El potente material jurídico presente en las notas que Giner escribió junto con Azcárate y González de Linares a la traducción de los tres volúmenes de la Enciclopedia Jurídica ahrensiana, apareció también reeditado en varios artículos del Boletín de la Institución Libre de Enseñanza (BILE), y después, por su especial relevancia, pasó a conformar el postrer volumen de las obras completas, GINER y AZCARATE, 1965.

9 AHRENS, 1878-1880: 90. 
encerrado en el bello honeste, o mejor, pie vivere. Todo lo que esto implica fundamentalmente a saber, carácter ético, espiritual del derecho, y reconocimiento de un aspecto inmanente en el mismo, eran razones suficientes para que Krause viese en Leibnitz un ascendiente ideal, al tratar de este problema ${ }^{10}$.

Este no es lugar para desarrollar la evolución del concepto del Derecho en tan diversos y destacados filósofos, pues tal labor excede el propósito de este estudio; baste señalar aquí la propuesta esbozada por Krause de lo jurídico como un juicio universal, como realización de un ideal, de un «deber ser», que no es expresión circunstancial de un momento histórico, pues el ideal del derecho «supera siempre su realización positiva; el derecho no se agota en el derecho positivo, ni este último realiza con ultimidad todo el contenido del ideal del derecho» ${ }^{11}$. La superioridad de este derecho ideal sobre las leyes establecidas, se manifiesta dentro de la tradición iusnaturalista como un principio que las orienta y que ayuda a decidir en casos de conflicto legal, estableciendo pautas para determinar la justicia o injusticia de una norma positi$\mathrm{va}^{12}$. Es patente la conexión de esta argumentación con los principios rectores que articulan las corrientes del iusnaturalismo clásico:

... su convicción de que el principio sobre el que se legitima toda ley debe ser un principio universal, no particular, y que la fundamentación de este principio es el resultado de una deducción a priori, no de una abstracción histórica. Éstos son los aspectos esenciales en los que Krause sigue prestando vasallaje a los principios del iusnaturalismo ${ }^{13}$.

En la rigurosa obra de Querol Fernández sobre La filosofía del derecho de $K$. Ch. F. Krause, se añade de modo inmediato a este reproche de un iusnaturalismo extremo presente en el krausismo, una argumentación que explica cómo Krause viene a subsanar los errores y excesos de la fundamentación abstracta, ahistórica y meramente racional de la vida real, en que incurría la filosofía del derecho natural del siglo XVIII y de la que se sustraería el propio filósofo alemán:

El naturalismo de Krause dista mucho de ser aquel naturalismo del siglo XVIII al que Conradi acusaba de abstracto, formalista y de haberse convertido en la filosofía de salón de los monarcas absolutistas. [...] A juicio de nuestro autor, los sistemas iusnaturalistas siguen, pues, cometiendo un error «[...] al reducir el campo del derecho natural, esto es, de la ciencia filosófico-jurídica, al supuesto ideal de un estado humano perfecto...», y no tener en cuenta que lo jurídico, como condición de

10 RÍOS URRUTI, 1915: 147.

11 QUEROL, 2000: 35-36.

12 ATIENZA, 2003: 94.

13 QUEROL, 2000: 66-67. 
posibilidad para la realización del humano, debe reconocer en los hombres no sólo el ideal (como conclusión), sino su evolución como organismo: sus distintas etapas, las diferencias individuales, las imperfecciones ${ }^{14}$.

Francisco Giner y su maestro Krause parten, pues, de la fundamentación iusnaturalista de la época moderna, pero ambos vienen a subsanar los excesos de ese iusnaturalismo puramente teórico, formal y dogmático de la filosofía del derecho del siglo XVIII, que reducía el derecho natural al supuesto de un estado humano perfecto. En su lugar, los krausistas exponen la evolución del ideal del derecho en la historia como organismo, como vida del derecho:

... el ideal jurídico no debe ser considerado como una norma que se puede exigir en su perfección y totalidad como pretendían los iusnaturalismos racionalistas. Krause no tiene una idea cerrada y estática del ideal jurídico, sino dinámica y evolutiva. El ideal se realiza a lo largo de la historia, y sólo se verifica progresiva y parcialmente a través de las leyes positivas ${ }^{15}$.

La postura de Giner también va más allá del iusnaturalismo racionalista del siglo XVIII, al otorgar mayor amplitud al contenido de la Filosofía del Derecho. Si para éste el Derecho no abarcaba el derecho histórico, sino sólo el conocimiento del Derecho y del Estado «en pura razón», en Giner se reconoce que la Filosofía del Derecho no debe limitarse sólo al estudio de lo que haya en el Derecho de razón, de ideal puro, sino que ha de comprender, para la realización orgánica del ideal de la condición humana, también todo lo particular y vario que se halle en lo jurídico, refiriéndolo a su unidad esencial. Así pues, la teoría de Krause, secundada por el krausismo español, representaría pues una actitud mediadora que vendría a superar «dos formas de dogmatismo»: de una parte, el positivismo jurídico de Hegel, y, por otra parte, el historicismo. Esta actitud sintética que presenta el conocimiento del ideal del derecho y su realización en una relación necesaria de complementariedad, también denominada como "derecho natural de contenido variable» ${ }^{16}$, es lo que Querol desarrollada detalladamente en su libro sobre Krause, donde se exponen algunas de las líneas de acción que se deducen de este compromiso práctico de la filosofía del derecho krauseana, que hereda Giner ${ }^{17}$.

14 QUEROL, 2000: 49-50.

15 QUEROL, 2000: 74-75.

16 QUEROL, 2000: 51.

17 MANZANERO, 20 (Madrid, 2015b): 47-62. 


\section{LA ARQUITECTÓNICA DEL DERECHO KRAUSEANO: UN ORDEN DE CONDICIO- NALIDAD}

Como se ha indicado, el sistema completo de las categorías del Derecho expuesto por Krause, tal y como fue desenvuelto metodológicamente por sus discípulos, pertenece a una larga tradición filosófica:

Estas categorías que Aristóteles derivó empíricamente del lenguaje, y que la filosofía escolástica con sagaz, aunque abstracto entendimiento, enlazó dogmáticamente; que Leibniz indagó con mayor profundidad, aspirando a construir sobre ellas su ciencia del lenguaje universal y Kant derivó y reorganizó, aplicándolas como principios regulativos a todas las ciencias; que Hegel consideró, como momentos de la evolución del absoluto, y Krause fundó de nuevo y ordenó en el sistema más completo hasta hoy, han de desarrollarse también de una manera sistemática en toda metodología jurídica un tanto extensa ${ }^{18}$.

A este respecto, conviene repasar la lectura que hace Ahrens de las categorías del Derecho de Krause y la exposición de los tres periodos de su desenvolvimiento. Es, reconoce Ahrens, mérito del propio Krause toda esta reforma de la doctrina de las categorías clásicas del Derecho, que él consideraba como una reforma imprescindible, y que sería la que posteriormente alcanzaría una mayor amplitud y desarrollo en España al ser recuperadas y reasumidas por los krausistas españoles:

Sólo Erdmann (aunque él admira sobre todo a Hegel) ha hecho notar en su fundamental Historia de la Filosofía moderna (Gesch. der neueren Philosophie), que únicamente dos filósofos, Hegel y Krause, han devuelto a la Filosofía una Metafísica con su sistema de categorías, que «asegura a Krause un alto lugar entre los filósofos alemanes»; y que «esos dos hombres (con sólo ya el intento de establecer un sistema de categorías y aunque no se esté de acuerdo con esas categorías o con el modo de deducirlas) merecen, por esta razón, el honor de haber reasumido todo lo que el desarrollo de la ciencia hasta entonces había presentido ${ }^{19}$.

Doce son las categorías krauseanas del Derecho que Ahrens recoge en la Enciclopedia Jurídica, a saber: 1. Unidad; 2. Seidad y sustantividad; 3. Todeidad o integridad (Ganzheit versus Totalität); 4. Unión; 5. Fundamento y causa; 6. Materia y forma; 7. Cantidad o magnitud y su determinación, 8. Cualidad; 9. Relación o referencia; 10. Las categorías del modo de existir, del modo de ser o de la modalidad, íntimamente enlazadas con la de la relación, a saber, necesidad, posibilidad y efectividad, con sus contrarias: accidentalidad,

\footnotetext{
18 AHRENS, 1878-1880: 34.

19 AHRENS, 1878-1880: 34-35.
} 
imposibilidad e inefectividad; 11. Formas de la existencia: tiempo y espacio; y 12. Principio de la consideración ${ }^{20}$. De las doce categorías del concepto del Derecho de Krause —que Ahrens expone en su Enciclopedia Jurídica, y que Giner tradujo al español y comentó junto con Azcárate y Linares-, se hace una labor de síntesis, de modo tal que quedan reducidas en la obra gineriana estas doce cualidades universales del Derecho a cinco principales pues - según Giner-, éstas comprehenden y resumen el sentido de las restantes. Encontramos pues en el concepto de Derecho gineriano las siguientes cinco categorías o principios elementales en que quedaría cifrado su pensamiento jurídico:

1. Unidad. Esta primera categoría concibe al Derecho como un orden homogéneo, del cual se derivan su carácter necesario y obligatorio. Esta unidad del Derecho se manifiesta en su historia, en el «espíritu común», que penetra el derecho positivo de cada pueblo, pues «la expresión de la unidad del Derecho es también la de la persona que lo cumple: el Estado» ${ }^{21}$. Una consecuencia práctica que se deriva de la aplicación de esta primera cualidad del Derecho es que Giner proponga como tertium medium entre las doctrinas federativa y la centralista, el carácter orgánico de la unidad del todo.

2. Sustantividad. Este principio general de la sustantividad del Derecho como un orden soberano e inviolable, se resuelve en dos conceptos que son fundamentales en la filosofía krausista: la autonomía y la autarquía. La autonomía es entendida como la ley y el criterio para su propia esfera, en cuya virtud, el principio jurídico se da la única ley para sus hechos. Y su otra faz, la autarquía, «por la que compete a cada persona la suprema dirección de aquellas de sus relaciones que le son privativas, como su único legislador y juez» ${ }^{22}$.

3. Totalidad. Esta categoría implica que cada lesión particular al Derecho no es sólo una agresión contra la persona lesionada, sino contra la sociedad en su conjunto. Con otras palabras, cada infracción del Derecho supone la lesión del orden jurídico entero, pues esta categoría de totalidad concibe al Derecho como indivisible e infinito: todo él está en cada relación particular jurídica, de modo que subsiste en cada parte.

4. Variedad. Ella se entiende en sus dos modalidades: 4.1. Como variedad referida al Derecho mismo como objeto: hay tantas esferas como fines para la vida. 4.2. Y como variedad según la persona que como sujeto

20 AHRENS, 1878-1880: 35-55.

21 GINER, 1926: 101.

22 GINER, 1916: 103. 
obligado lo cumple, lo cual se entiende asimismo, desde una doble perspectiva: a) como variedad «permanente», fundada en el organismo de la personalidad. b) y como variedad «histórica» o evolución efectiva del Derecho ${ }^{23}$.

5. Armonía. Este precepto quizá constituye la nota más distintiva de la filosofía krausista, y consiste en la organicidad de las relaciones o la presencia del todo en cada parte. Algunos corolarios que pueden deducirse de esta categoría son: 5.1. La igualdad de las relaciones jurídicas, así como 5.2. La armonía y solidaridad entre las relaciones interiores del Derecho.

Este mismo principio inspirador de base krauseana que sirve a Giner para exponer las cinco categorías del concepto de Derecho, se encuentra también presente en la definición fundamental que Giner ofrece de los tres periodos del desenvolvimiento de la ciencia del Derecho: general, especial y orgánica. A) la parte «general», considera el Derecho que «es» y que «debe ser» considerado primeramente como un solo objeto. Esta primera parte de la Filosofía del Derecho estudia analíticamente el Derecho «en sí», en su esencia y, por tanto, trata de sus cualidades esenciales, es decir, de las tres primeras categorías: unidad, sustantividad y totalidad; b) la parte «especial» se resuelve según el principio general de la variedad en el Derecho, que trata de la distinción interior del Derecho en instituciones especiales históricas organizadas según la variedad permanente de los fines de la vida en que se revela el Derecho: de la personalidad, de bienes, político, penal, etc. ${ }^{24}$; c) por último, en la parte «orgánica» se expone el sistema de las esferas graduales en que se cumple la relación del Derecho como un todo con sus instituciones especiales. La organicidad de estas relaciones se basa en la categoría de la «armonía» krausista, cuyos matices pueden apreciarse, tanto en los fundamentos de su filosofía jurídica, como en la acomodación de los principios del Derecho a los hechos.

Para una comprensión adecuada de los citados principios krausistas del organicismo y la armonía, debe recordarse que para Krause, y, en general, para todos los pensadores krausistas, una propiedad inherente al concepto de Derecho es la de la «condicionalidad», cuyas determinaciones toma de la filosofía de Leibniz. Por este aspecto de la «condicionalidad» en el Derecho también mostró interés Ahrens: «El concepto de condición ha sido todavía poco indagado y desarrollado en todos sus sentidos: Leibnitz ha iniciado esta indagación en su extenso ensayo Doctrina de conditionibus (como un specimen certitudinis sive demonstrationis in jure)...; IV: 29-159; pero considera principalmente la

23 GINER, 1916: 16.

24 GINER, 1926: 35. 
condición sólo en el sentido de co-determinación» ${ }^{25}$. Así expresa Sanz del Río en su artículo sobre «El Derecho y el Estado, según Krause», esta definición de la esencia del derecho como «condicionalidad», presente en la obra de Krause, donde el Derecho queda inextricablemente ligado a «la vida en su condicionalidad libre para su fin ${ }^{26}$. Concebido el mundo de condiciones como una unidad orgánica es como aparece en la sistemática de Krause la ciencia del derecho. También es definida en formulaciones más concisas como «el todo de las condiciones que ha de prestar la voluntad humana para la realización de los fines de la vida» y como «el todo de condiciones para la vida racional (esto es, moralmente buena) del individuo y de la sociedad humana» ${ }^{27}$.

Atendiendo a la exposición de la Enciclopedia Jurídica de Ahrens localizamos tres elementos en esta definición del Derecho krauseana como condicionalidad: a) la condición condicionante: esto es, un elemento «objetivo» que sería el fin racional de la vida, dado en el bien moral; b) lo condicionado: que sería el elemento «subjetivo» constituido por la voluntad del hombre; c) $\mathrm{y}$, al mismo tiempo, el mutuo determinarse lo coexistente (das Sicheinanderbestimmen des Zugleicheienden), es decir, la «relación» entre ambos, como expresara Clarín en su tesis doctoral sobre «El derecho y la moralidad» publicada en fascículos en la Revista Europea ${ }^{28}$.

De acuerdo con esta determinación tripartita de la naturaleza condicional del Derecho, los krausistas tienen en cuenta, no sólo la base objetiva, sino también la subjetiva del Derecho, pues la condición, «que en sí misma, como dada en razón del fin, es objetiva también, [...] tiene en la voluntad, que ha de prestarla, un punto de partida subjetivo» ${ }^{29}$. La condicionalidad sería, por tanto, según esta indagación, una relación bilateral entre lo condicionado y lo condicionante. El concepto enciclopédico y filosófico-jurídico de la condicionalidad viene a ser, por tanto, el de «aquello que se requiere para que el determinado sea» $\mathrm{y}$, más concretamente, «aquello de que depende la acción individual y social, en tanto que se refiere a fines de la vida racionales, moralmente buenos ${ }^{30}$. Tal definición de la condición como relación interna y formal, al mismo tiempo, denota la preocupación krausista por esa dimensión interna del derecho, lo cual implica no sólo la suposición, sino la necesidad de que una cosa exista, para que exista la otra. Es decir, el Derecho no queda varado en un plano formal, sino que reclama que a los individuos se les haga

25 AHRENS, 1878-1880: 102-103.

26 SANZ DEL RÍO, 1882b: 198.

27 AHRENS, 1878-1880: 38.

28 ALAS, 1878: 533.

29 AHRENS, 1878-1880: 38.

30 AHRENS, 1878-1880: 39. 
posible (condición) el realizar y cumplir sus fines, mediante su propia causalidad y esfuerzo (autonomía).

De este concepto metafísico de la condicionalidad nace y se deduce el concepto de Derecho, circunscrito a la vida humana que ha de prestar la actividad de la voluntad racional, donde las relaciones entre personas se revelan en pretensiones y obligaciones para su voluntad. Por lo tanto, esta condicionalidad — según la cual las relaciones de la vida se encuentran recíprocamente determinadas - , se da tanto en la «esfera interior de vida (física y psíquica) [de cada hombre], donde él mismo ha de ordenar en propia (interna) justicia la condicionalidad mutua de sus términos, cuanto en su vida y comercio social, en la cual han de producirse en común las condiciones de una vida y conducta racionales ${ }^{31}$.

La consideración de la relación de Derecho no referida con exclusividad a las relaciones exteriores entre las personas sociales o individuales, sino concerniente también a la conducta de cada cual consigo mismo, constituye uno de los tópicos primordiales en la filosofía krausista. Una de las principales conclusiones que se derivan de la suficiencia interior y fundamentalidad del Derecho como un género integrador orgánico de la vida, es que hay ciertos derechos fundamentales que son inviolables, es decir, que «llevan en sí su propia fuerza obligatoria», «aún respecto de la Moral y la Religión» ${ }^{32}$.

En virtud de este principio condicional del krausismo, la teoría jurídica krausista ha coadyuvado a la consolidación de los derechos humanos, cuyo desenvolvimiento se pone de manifiesto en cuestiones relativas a la existencia de un Derecho inmanente y un Derecho internacional de base krausista ${ }^{33}$.

Poniendo fin a esta sección de introducción al concepto de Derecho krauseano, resumiremos su talante, su modo de ser más propio, repasando sucintamente las importantes transiciones y enmiendas que esta filosofía presupone y que se cifran básicamente en: el paso de un Derecho exterior y coactivo a un Derecho fundado en la esencia interior del individuo; de arbitrario e irregular a fundamental y orgánico; y a la transformación, en definitiva, de un Derecho particular o nacional, a ser, a la postre, un Derecho universal humano.

\section{Cuatro enMiendas de Giner a la filosofía del derecho de H. AHRENS}

La filosofía del derecho de Ahrens desarrolla y sigue fielmente el concepto del Derecho de la doctrina de su maestro, Krause, como hemos tenido ocasión de exponer en la teoría del organismo y de la libre condicionalidad del Derecho

31 AHRENS, 1878-1880: 42.

32 SANZ DEL RÍO, 1882a: 42.

33 MANZANERO, 265/71 (Madrid, 2015a): 53-71. 
ilustrada más arriba. Sin embargo, Ahrens se distancia de su mentor en algunos aspectos que resultan cruciales para poder comprender la recepción y reevaluación que se hace del concepto de Derecho krauseano en la obra jurídica y social de algunos krausistas españoles como Francisco Giner de los Ríos.

Antes de entrar a comentar las enmiendas que Francisco Giner dirige a Heinrich Ahrens, es preciso realizar en primer lugar un análisis conciso de la postura de este filósofo y jurista alemán que nos sirva de trasfondo para poder reparar en los aspectos fundamentales de su doctrina, a fin de detenernos luego en las cuestiones jurídicas concretas a que se dirigen las objeciones de Giner.

En participar, Ahrens se distancia de la doctrina jurídica krauseana cuando interpreta el concepto del Derecho como habiéndole ya en la relación exterior condicional, es decir, en su carácter relativo, lo cual parece inducir a Ahrens - afirma Giner - , a considerar la relatividad y la reciprocidad como notas esenciales del Derecho. Así viene explicada en palabras del propio Ahrens esta marcada distinción que media entre Derecho (como un orden exterior) y la Moral (en tanto que orden interior):

... a Moral, en la cual nadie puede sustituir a otro, por ser sus deberes y virtudes siempre preceptos absolutos para la propia e independiente acción de cada cual en determinada cualidad de voluntad; en tanto que el Derecho, por su carácter relativo y condicional, regula también relaciones exteriores que nacen de la dependencia y necesidad de complemento entre los hombres ${ }^{34}$.

En efecto, Ahrens fundamenta en esta determinación del concepto del Derecho como un orden exterior y relativo, en la que hace residir la razón de la distinción entre el derecho y la moralidad:
... aquí puede expresarse la diferencia entre la moralidad y el derecho. Consiste la primera en la propia determinación para fines racionales: el segundo, en el recípro- co determinarse unos a otros para estos fines. De suerte, pues, que en el organismo de la vida humana, deben ordenarse las condiciones de la vida racional para el in- dividuo y para la comunidad social, ora se procuren por la actividad individual, ora por la social ${ }^{35}$.

De acuerdo con esta particular distinción que Ahrens introduce entre Moral y Derecho, según la cual dichas esferas tienen ámbitos distintos de aplicación por pertenecer ambas a distintos órdenes —interioridad y exterioridad, respectivamente-, Ahrens establece, de modo coherente con esta definición, una serie de casos prácticos en que el Derecho no debe recurrir a la Moral. El caso práctico por antonomasia invocado por la filosofía jurídica en que el

34 AHRENS, 1878-1880: 30.

35 AHRENS, 1878-1880: 42. 
Derecho no debe recurrir a la Moral en orden a preservar la autonomía del sujeto, es el de aquellos actos que atañen a la esfera privada del individuo. Ahrens reconoce así la existencia en la esfera del Derecho inmanente, en el propio círculo interior de acción de una persona, la «libre disposición y soberanía» para que toda persona social o individual pueda proseguir los fines que quiera, y en la forma moral y jurídica que le plazca, con sólo atenerse a las generales que prescribe el Derecho. Es en esta esfera privada individual donde «se puede y debe prescindir en casos determinados de los motivos morales que no caen en la esfera de la apreciación exterior» ${ }^{36}$. Incluso llega a afirmar Ahrens que «cada persona puede en su esfera privada individual hacer de sus derechos un uso completamente arbitrario y hasta inmoral, sin tener que someterse al fallo jurídico de un tribunal exterior ${ }^{37}$.

Ahrens añade a estas palabras varias precisiones a fin de aclarar que este trato del Derecho con lo inmoral no consiste en una relación positiva, es decir, que el Derecho no «permite» su existencia, sino que tiene la aspiración moral — cuyos medios, subraya Ahrens, nunca podrían ser coercitivos- y pone todo su empeño en fundamentar y constituir sólidamente «una Ciencia ética del Derecho en que todos se penetren de la obligación fundamental en que se encuentran de usar moralmente, ante Dios y ante su conciencia, de su derecho, aun en la esfera privada» ${ }^{38}$. La expresión de esta distinción entre el Derecho y la Moral que Ahrens establece puede leerse en puridad en las siguientes líneas: «el Derecho no ha de inquirir ante todo las intenciones, sino que debe limitarse a «examinar» la ocasión y fundamento, base de actos externos, y «en determinados casos» a sus motivos morales, que ha de «tomar en cuenta» para la formación del acto jurídico» ${ }^{39}$.

La razón por la cual hemos recogido este fragmento en que Ahrens reconoce que existen determinados casos en los que la moral sí importa al Derecho, es para dejar constancia de que, a pesar de que Ahrens sigue una línea de pensamiento kantiana al atribuir, sin asomo de duda, la nota de exterioridad al Derecho y de interioridad a la Moral, sin embargo, tal distinción es matizada por el propio Ahrens al reconocer la existencia de una esfera de derecho propio e íntimo del sujeto que sí importa al Derecho, volviendo así a converger con la línea de pensamiento marcada por la filosofía krausista. Ciertamente la riqueza y versatilidad de la filosofía jurídica de Ahrens no le hace ser un blanco fácil de críticas. En tal sentido, no siempre las objeciones que le hace Giner representan una postura antagónica completamente desacorde con sus ideas, al contrario, vemos cómo en estas definiciones de la relación entre De-

\footnotetext{
36 AHRENS, 1878-1880: 53.

37 AHRENS, 1878-1880: 57.

38 AHRENS, 1878-1880: 57.

39 AHRENS, 1878-1880: 54.
} 
recho y Moral, Ahrens no termina de precisar ni clarificar en qué consiste esta relación y es, precisamente ahí, en su oscilación constante entre dos ideas antagónicas, donde Giner dirige sus revisiones y comentarios más certeros en orden a matizar y clarificar la vaguedad con que Ahrens describe esta relación entre Derecho y Moralidad.

Para no caer en simplificaciones que podrían trastocar el valor de las aportaciones de estos autores, véase brevemente la otra dimensión de la postura de Ahrens, aquélla que más le determinó como krausista, al defender que la ética también importa e incumbe al Derecho. En primer lugar, debe indicarse que la filosofía del derecho de Ahrens se opone abiertamente a la regla de la tradición iusromanista que ordena prescindir absolutamente de todos los motivos morales - una tradición de la que Ahrens era gran conocedor como autor del Compendio de la historia del derecho romano, que fue traducido de la versión directa del alemán con notas críticas por Giner, Azcárate y Linares ${ }^{40}$ Por el contrario, Ahrens reconoce que hay excepciones en el Derecho privado, en el Derecho Penal o Criminal e incluso en el Derecho Público, donde los motivos morales importan al Derecho. Obsérvese cómo describe estas particulares coyunturas jurídicas en cada una de las tres citadas categorías, empezando, en primer lugar, por el Derecho Privado; aquí Ahrens se muestra de acuerdo con la intervención jurídica en la esfera del Derecho privado en los siguientes casos:

... todo empleo inmoral que de él haga (v. gr., en el derecho de propiedad, la disipación de su fortuna) lleva por lo general a una injusticia contra sí propio y contra los demás, por lo cual autorizan también las mismas leyes positivas, fieles en esto a un mejor concepto del Derecho, una intervención jurídica ${ }^{41}$.

Este recurso en el Derecho a la Moral se pone de manifiesto no sólo en el ámbito del Derecho privado, sino que también concierne muy especialmente al Derecho Penal donde, para Ahrens, «siempre» es preciso tener en cuenta las determinaciones internas morales con que ha sido ejecutado el acto punible:

\footnotetext{
Así se muestra, [...] en los deberes y virtudes morales, los cuales, en cuanto se exteriorizan en actos y son condición de una relación de la vida (el amor y la fidelidad en el matrimonio, el amor en los hijos, etc.), pueden tener también efectos jurídicos; y no acontece menos en el Derecho penal, donde, al juzgar un hecho externo, hay que retroceder a tantos elementos morales de que depende la culpabilidad ${ }^{42}$.
}

\footnotetext{
40 AHRENS, 1879.

41 AHRENS, 1879: 57.

42 AHRENS, 1878-1880: 24.
} 
Por lo tanto, el hecho de que Ahrens distinga entre Derecho y Moral no significa para él que se haya de prescindir por completo de las intenciones en la calificación jurídica. Este pensamiento sigue teniendo vigencia hoy en día, por ejemplo, podemos pensar en los diversos grados de culpabilidad dentro del Derecho penal que se valoran según la intencionalidad, por lo que cuestiones éticas como las citadas son, de hecho, tomadas en cuenta en la aplicación del Derecho. Más aún, dice Ahrens, el orden jurídico positivo no sólo recurre a la Moral en estas esferas del Derecho privado y el Derecho Penal, sino que incluso se recurre a la Moral en el Derecho público, lo cual se manifiesta de forma patente cuando se toman en cuenta «ciertos criterios y reglas, ya generales, ya particulares, encaminados a aquel fin, así como es preciso atemperarse también ante todo al estado y cultura moral de cada pueblo, al establecer la norma de su constitución y régimen administrativo» ${ }^{43}$.

En definitiva, lo que Ahrens fundamentalmente pretendía con esta distinción entre Derecho y Moral, según la cual, el Derecho remite a los actos externos y la Moral a los actos internos, no era decir que la Moral no se interesa para nada por los resultados externos, sino evitar que el Derecho invadiese zonas que él consideraba como intangibles, las zonas precisamente de la libertad de pensamiento y de conciencia. Quizá lo que buscaba Ahrens al establecer esta distinción era limitar lo jurídico al campo de los deberes externos del hombre con respecto de los demás hombres, mientras que la dimensión ética atañería tanto al campo de los deberes internos (donde esa libertad era defendida) como al campo de los deberes externos. Según esto, lo decisivo para Ahrens sería esta idea clave de que la moralidad de la acción, en cuanto algo interior, no puede subordinarse a las leyes humanas públicas, porque éstas se refieren sólo a la legalidad de las acciones. Por lo tanto, como puede apreciarse en los fragmentos citados de la obra de Ahrens, él sí pensó que la ética incumbía también al campo de los deberes externos, aunque siempre situando el peso de la calificación moral en la intencionalidad, en el obrar por estímulo del deber, lo cual, de alguna manera, ya venía a desdibujar esa distinción tan tajante entre derecho y moralidad.

Resumidas pues las caracterizaciones del concepto de Derecho y las múltiples relaciones que Ahrens establece entre el Derecho con la Moralidad - cuya vinculación y relación él reconoce como algo deseable, acentuando así esa referencia intencional a la justicia inherente a su concepto del derecho-, expondremos a continuación las cuatro principales enmiendas que Francisco Giner dirige a Heinrich Ahrens en los comentarios críticos que realiza a la Enciclopedia Jurídica.

\footnotetext{
43 AHRENS, 1878-1880: 54.
} 
1. La primera enmienda se refiere a la distinción entre Moral y Derecho fundada en la supuesta interioridad/exterioridad respectiva de ambos órdenes a que antes hemos aludido. Como se ha señalado anteriormente, a pesar de que Ahrens reconoce los casos citados de mutuas avenencias entre el Derecho y la Moral, en el derecho público como en el derecho privado, añade una delimitación a estos dos ámbitos normativos contra la que Giner discrepa: «la limitación de que el Derecho jamás abraza sino un aspecto de las relaciones de la vida, a saber, aquel en el cual manifiestamente se «condicionan» ${ }^{44}$, distinguiéndolo, por tanto, de la Moral como la esfera de las intenciones. Así lo enuncia con contundencia Ahrens: «La actividad puramente interna de la voluntad queda fuera del Derecho, perteneciendo a la esfera de la moral $»^{45}$.

Las objeciones de Giner se dirigen precisamente contra esta distinción entre Moral y Derecho fundada en la interioridad/exterioridad respectiva de ambos órdenes. Leopoldo Alas Clarín, discípulo de Giner, le secunda en esta idea y critica a Ahrens por idénticos motivos: «El derecho, a pesar de ser relación del acto al fin del objeto, es con todo, puramente interno, en rigor, sin que el ser para el fin del objeto, como así es, le dé ese carácter interno-externo que han creído necesario autores tan perspicuos como Ahrens ${ }^{46}{ }^{46}$. Esta idea la toma Clarín de Giner cuyo influjo en su obra y reconocida tutela es patente, tal y como se pone de manifestó en un fragmento de su tesis doctoral El Derecho y la Moralidad, en cuya edición puede leerse la siguiente dedicatoria «A don Francisco Giner del Río [...] su sincero amigo y reconocido discípulo». En efecto, tanto Giner como Clarín consideran que el Derecho alcanza también al interior, a la conciencia y a la voluntad del hombre, de tal manera que la esfera del derecho se corresponde y coincide "cuantitativamente» con la moral, constituyendo así lo que Giner denomina el Derecho Inmanente de la persona ${ }^{47}$. Un principio de derecho «interno» al que Ahrens, tampoco era ajeno y conocía perfectamente, si bien en su obra quedaba éste restringido a la esfera de la moral:

La actividad interna pertenece al derecho interno, cuya esfera cuantitativamente coincide con la moral; la actividad interna exteriorizada al derecho exterior individual y social; y cuando esta exteriorización reúne ciertos caracteres, cae dentro de aquella parte del derecho social que se halla sometida al gobierno de los poderes públicos $^{48}$.

Las enmiendas de Giner a Ahrens no fueron recogidas únicamente en las anotaciones y comentarios que hizo a la traducción española de la Enciclope-

44 AHRENS, 1878-1880: 24 y 82.

45 AHRENS, 1878-1880: 24 y 82.

46 ALAS, 1878: 441.

47 DÍAZ, 1973.

48 AHRENS, 1878-1880: 82. 
dia Jurídica de Ahrens, sino que también aparecen algunas de ellas en artículos del Boletín de la Institución Libre de Enseñanza (BILE), como el titulado «Sobre lo moral y lo jurídico», donde se reproduce una de las notas críticas que Giner publicó en el tomo II de la Enciclopedia Jurídica de Ahrens, y en la que se realiza un interesante excurso histórico sobre esta cuestión que, por su interés y su referencia expresa a las deficiencias que él ve en la doctrina de Ahrens, consideramos oportuno reproducir aquí textualmente para aclarar el significado de su doctrina:

En general, sobre este punto de la significación del interior y ético en el derecho, reinan dos corrientes: a) la kantiana, que divorcia, más o menos absolutamente, lo ético de lo jurídico; b) la que como Hegel, Stahl, Taparelli, Trendelenburg, etc., aspira a concertar ambos principios. Pero una y otra tendencia tienen de común el considerar interno y externo como respectivamente equivalentes a moral y jurídi$c o$, y al proclamar que todo derecho es coercible y social; la divergencia estriba en querer, los unos, que ambos órdenes se separen; los otros, que se mezclan e identifiquen, más o menos íntimamente. Mientras subsista esta base común (a que Ahrens se inclina aquí), el concierto entre ambas tendencias es imposible, o por mejor decir, es imposible otro concierto que el que esa unidad común supone ${ }^{49}$.

En varias notas a la Enciclopedia Jurídica de Ahrens, Giner expone las inexactitudes y errores en las que el jurista alemán incurre en su estimación del Derecho. Uno de los puntos de divergencia más importantes y donde mejor se pone de manifiesto la insuficiencia de la definición ahrensiana de la relación entre Derecho y Moral, se encuentra en su consideración del derecho privado. Las enmiendas de Giner se destinan pues a mostrar la inconsistencia de una doctrina que, como la de Ahrens, en ocasiones parece querer mantener al mismo tiempo las tesis contrarias del kantismo con las del krausismo, dando así lugar a paradojas e incoherencias en su doctrina derivadas de su propia incompatibilidad:

Pero a) si toda obligación propiamente jurídica es coercible, como explícitamente piensa Ahrens, con Kant y toda la escuela naturalista y dominante; $b$ ) si todo abuso constituye una infracción del derecho; y c), si no por esto cabe hacer intervenir siempre al Estado para remediar la injusticia, ¿cómo concertar estas tres afirmaciones? en la imposibilidad de hacerlo, tiene por precisión venir a parar en el expediente de asignar un límite vago y arbitrario [...] al círculo dentro del cual puede el propietario obrar a su albedrío, sin incurrir en responsabilidad ante las autoridades públicas. Pero esto no es fácil cohonestarlo — afirma Giner - con la extraña declaración de que, dentro de ese círculo, el principio ético «sólo puede aparecer jurídicamente de un modo secundario y limitativo» ${ }^{50}$.

49 GINER, 1878b: 175.

50 GINER, 1878a: 145. 
Los puntos de divergencia entre las teorías de estos dos autores respecto a la relación entre Derecho y Moral pueden resumirse en dos principales puntos de desencuentro. En primer lugar, Ahrens estima al Derecho principalmente como relación social, frente a Giner, que defiende la existencia de un Derecho inmanente en cada persona. En segundo lugar, Ahrens concibe el Derecho como sometido siempre y en todo su contenido y sus esferas a la autoridad de los poderes públicos del Estado. Mientras que Giner hace notar que, en esta definición, Ahrens olvida determinar cómo a cada persona corresponde un círculo privado de libre actividad exterior y que toda resolución debe confiarse exclusivamente a la persona que ha de fallar por sí misma en cada caso, como la única que posee todos los elementos necesarios para formar un juicio racional $^{51}$. Esta resolución, por tanto, no corresponde al Estado —oficial ni social, especificamos, ya que Giner también hablará de la existencia de un «Estado social» y un «Estado individual»-, sino que corresponde, en mayor o menor medida, a la libre decisión de todo sujeto, de todo ser racional en su círculo de acción inviolable, según el estado del desarrollo de la plenitud de sus funciones ${ }^{52}$.

En definitiva, la cuestión que aquí plantea Giner, y con la que interpela a Ahrens, es la de responder a la crucial decisión de si el contenido de esa esfera inmanente, que efectivamente se halla sustraída a la acción e intervención de los poderes públicos, pertenece o no, sin embargo, al Derecho. La tesis de Ahrens, nos permite, en efecto, afirmar que el Derecho no debe intervenir en los actos que no se exteriorizan, en los actos que permanecen a nivel de pensamiento, de intención o de creencias, lo cual ha sido y continúa siendo enormemente importante para preservar la libertad de conciencia, y puede considerarse, sin lugar a dudas, como una conquista civilizatoria de la modernidad irrenunciable.

Sin embargo, quizá Giner no andaba tan errado al hacernos ver que hay un punto débil en la argumentación de Ahrens, al tratar de establecer la distinción entre Derecho y Moral sobre la base de dividir tajantemente las acciones en internas y externas. A poco que reflexionemos sobre ello, observamos que esta distinción carece de fundamento, puesto que todos podemos claramente identificar que hay actos que, en efecto, no trascienden al exterior, que no se manifiestan externamente, y que pueden ser denominados como actos internos exclusivamente, por ejemplo, los actos de pensamiento, intención, etc. Pero no podemos decir, en el mismo sentido, que haya actos puramente externos, porque todo acto humano posee una vertiente interior, una zona de

51 Ver VÁZQUEZ-ROMERO, 63/236 (Madrid, 2007): 199-234.

52 La complexión y alcance del «Estado social» y el «Estado individual» en la obra de Francisco Giner es un tema que ha sido brillantemente desarrollado en el artículo de VÁZQUEZ-ROMERO, 2009: 38 y ss. 
intencionalidad, de reflexión,... En definitiva, el acto interior está siempre muy presente, y en tal sentido, Giner estuvo muy acertado al incidir en esa carga interna y moral del Derecho, en esa esfera de Derecho inmanente. Por esta misma razón, se ha propuesto hoy en día diferenciar, con una nueva terminología bastante generalizada, entre actos interiorizados (es decir, actos que no se exteriorizan) y actos exteriorizados, una expresión que vendría a sustituir a la de «actos exteriores», y que mejora los problemas que tenía aquella expresión, puesto que al hablar de actos «exteriorizados» no estamos negando que exista una dimensión interna en ellos ${ }^{53}$.

Dicha reflexión contemporánea sobre este aspecto o dimensión interna del Derecho — tan invocada por los filósofos del derecho krausistas-, ha permitido a un gran teórico iuspositivista del siglo XX como H. L. A. Hart aclarar conceptos o fenómenos jurídicos que el positivismo decimonónico inglés explicaba de manera insatisfactoria, como por ejemplo, la noción del deber jurídico.

Es probable que la vida de cualquier sociedad que se guía por reglas, jurídicas o no, consiste, en cualquier momento dado, en una tensión entre quienes, por una parte, aceptan las reglas y voluntariamente cooperan en su mantenimiento, y ven por ello su conducta, y la de otras personas, en términos de las reglas, y quienes, por otra parte, rechazan las reglas y las consideran únicamente desde el punto de vista externo, como signos de un posible castigo. Una de las dificultades que enfrenta cualquier teoría jurídica ansiosa de hacer justicia a la complejidad de los hechos, es tener en cuenta la presencia de ambos puntos de vista y no decretar, por vía de definición, que uno de ellos no existe ${ }^{54}$.

Mencionar esta problemática del deber jurídico supone introducir en la explicación del concepto de derecho la manera en que el grupo contempla su propia conducta, lo cual implica referirse al aspecto interno de las reglas, al punto de vista interno del sujeto ${ }^{55}$. Las implicaciones de la consideración de este punto de vista interno del Derecho, del punto de vista del partícipe en la vida del Derecho que acepta o interioriza las normas como pautas de conducta recíprocamente exigibles entre los miembros del grupo social, y que se apoya en ellas para expresar críticas hacia las conductas desviadas o para reclamar a cualquiera el comportamiento correcto - tal y como fueron expuestas de modo visionario por krausistas españoles como Giner de los Ríos-, resultan cruciales en el marco de filosofía jurídica krausista donde se postula una manifiesta moral interna en el derecho. Sobre esta común referencia de Ética y Derecho a los actos exteriorizables, según la cual, en los actos exterio-

53 DÍAZ, 1976: 19.

54 HART, 1977: 113.

55 RAMOS, 2007: 331-364. 
rizables hay siempre la participación de un acto interno, muestra Giner cómo en esta conexión esencial hayan su fundamento las verdaderas garantías del derecho. Aquí radica pues una de las tesis más interesantes del legado jurídico gineriana: la profunda significación ética que posee su concepto del Derecho.

2. La segunda enmienda de Giner se dirige contra la reciprocidad y la relatividad con que estarían caracterizadas, según Ahrens, las relaciones jurídicas. Como se ha indicado, para Ahrens, Moral y Derecho representan las dos formas en que la voluntad realiza el bien, las cuales se distinguen en que: a) mientras que la Moral trata de los bienes formales o absolutos, realizados incondicionalmente por el carácter incondicional del bien en sí mismo; b) el Derecho, por su parte, se ocupa de los bienes materiales, que constituyen el fondo del bien y que, siendo finitos o condicionales, dependen de las circunstancias de la vida. Según Ahrens, «es moral ante todo un acto de gratitud o benevolencia; pero, al exteriorizarse, toma a la vez carácter jurídico» ${ }^{56}$, y en este sentido, un carácter relativo y condicional:

Realmente es el Derecho una parte del bien, pues éste abraza a todo lo esencial que ha de ser realizado en la vida; pero es, sin embargo, el Derecho sólo un bien formal, lo mismo que la moralidad, constituyendo ambos dos formas o modos de realizarse el bien, que en la moralidad se cumple sin condición alguna, y en el Derecho bajo las relaciones mutuamente condicionales de la vida ${ }^{57}$.

Giner disiente sobre esta cuestión particular planteada por Ahrens, pues, según este gran pedagogo y jurista español, en esta distinción pareciera como si el Derecho no fuera «tan absoluto e incondicional en su naturaleza» como aquella, y que la moralidad no está sometida, al par del Derecho, a idéntica modificación y cambio «en su desarrollo» ${ }^{58}$. En este sentido - aclara Ginerninguna teoría que, más o menos explícitamente ponga la distinción entre la Moralidad y el Derecho en que éste se refiera al contenido material («objetivo», en palabras del propio Ahrens) del hecho, y aquella, a la intención subjetiva, puede ser consecuente ni precisa.

A las dos definiciones del Derecho y Moral planteadas por Ahrens, ofrece una réplica Giner en la que se destaca, respectivamente, la cara contraria: la Moralidad no sólo posee ese fundamento absoluto que Ahrens no reconoce suficientemente, sino que $-\mathrm{y}$ aquí invoca Giner a la tradición positivista—, también presenta un elemento progresivo e histórico. Asimismo, por su parte, - insiste Giner-, el Derecho no es un mero concepto relativo y condicional,

56 AHRENS, 1878-1880: 53.

57 AHRENS, 1878-1880: 61.

58 Nota de Giner en: AHRENS, 1878-1880: 34. 
sino que, en su fundamento, sería tan absoluto e incondicional como la Moralidad, en la que encuentra su fundamento y legitimación. Estos aspectos son los que Giner enmienda y matiza de la doctrina de Ahrens, al hacer hincapié en la objetividad del Derecho y la variabilidad e historicidad de la moral, cuyos fundamentos Giner no entiende de modo absoluto.

3. Una tercera estimación de Giner a la Enciclopedia Jurídica de Ahrens plantea una rectificación a la base antropológica de su teoría y a su concepción del Derecho basada en las limitaciones congénitas humanas ${ }^{59}$. Ahrens sostiene que el Derecho nace de la insuficiencia y condicionalidad inherentes a la limitación humana $y$, de acuerdo con este punto de partida, su doctrina atribuye al Derecho un carácter puramente social que termina poniendo en la coercibilidad exterior su nota distintiva ${ }^{60}$.

Giner combate esta teoría que identifica a la coacción como el elemento esencial del Derecho, con los mismos argumentos con que se opone a la escuela teológica del voluntarismo y su tesis de que el orden jurídico está «destinado a suplir la imperfección radical de la voluntad, a consecuencia de la caída de nuestros primeros padres, y a contener y reprimir sus excesos mediante la fuerza ${ }^{61}$. En su lugar, y siguiendo en esto escrupulosamente a Krause, Giner fundamenta el Derecho en un principio de carácter humano positivo: las condiciones de que depende mi fin de hombre.

Otros autores krausistas españoles, como Leopoldo Alas Clarín y Fernando de los Ríos, también han incidido y reflexionado sobre esta enmienda de Giner a Ahrens, consignando sus críticas a Ahrens y retomando para ello la argumentación gineriana. Así, por ejemplo, afirma Clarín que «Ahrens, con haber trabajado tanto por la [sic] análisis del concepto del derecho, no sale de la idealidad $»^{62}$. Y añade el sobrino de Giner, Fernando de los Ríos Urruti (1879-1949), quien estudió en la Institución Libre de Enseñanza mientras su tío la regentaba y publicó una obra fundamental de obligada mención sobre La Filosofía del Derecho en Don Francisco Giner ${ }^{63}$, plantea la siguiente reflexión en torno a esta cuestión:

Repárese en la dificultad con que tropiezan quienes fundan el Derecho en cualidades negativas de la naturaleza humana, en privaciones como el pecado (escuela teológica cristiana y muy especialmente San Agustín), en instintos de animosidad, Hobbes, en nuestra limitación e imperfección, como acontece a muchos, por ejemplo, al propio Ahrens, cuando intentan justificar el valor eterno del Derecho y para

\footnotetext{
59 Ver PAYO, 2012.

60 AHRENS, 1878-1880: 30.

61 AHRENS, 1878-1880: 94.

62 ALAS, 1878: 327.

63 RÍOS URRUTI, 1916.
} 
tomar posiciones ante los que, identificando lógicamente el Derecho con su corolario inseparable, si se toma tal punto de partida, la coacción, consideran es necesario luchar contra el Derecho64.

Así pues, Ahrens sigue esta tradición de pensamiento del voluntarismo de San Agustín y el estatalismo hobbesiano, que ofrecía una descripción pesimista de la naturaleza del hombre con base empírica y realista. A diferencia de la tradición clásica que partía de una imagen ideal del hombre como un ser fundamentalmente virtuoso, racional, social, como «animal político», esta perspectiva pesimista — con el Leviatán de Hobbes a la cabeza como uno de los filósofos realistas más prominentes-, caracterizaba al hombre con las notas distintivas del egoísmo y el ansia de poder que llevaba a la guerra de todos contra todos. Este choque producido por el ansia de dominio, que ponía en peligro la existencia de cada uno, tenía una función doble: pues no sólo les empujaba a mantenerse unidos («carácter centrípeto») por ese afán de dominio, sino que, al mismo tiempo, la fuerza contraria del miedo recíproco llevaba a los hombres a mantenerse a cierta distancia, a apartarse unos de los otros («carácter centrífugo»). De esta base natural que establece que los hombres tienden primariamente a la lucha y la discordia, se desprende la necesidad de limitar y contener esos instintos y movimientos anímicos de los hombres por un poder que sea capaz de evitar la lucha de unos con otros. Se trata pues de buscar un orden para seres imperfectos, que sea realmente útil o capaz de superar el caos del estado de naturaleza para establecer un orden real, donde al menos se haga viable la coexistencia. Es claro que para dicha teoría hobbesiana, el valor principal es el de asegurar una seguridad jurídica mínima que permita la coexistencia de esos individuos destructivos y egoístas, y esto sólo puede venir dado por el Estado:

El poder soberano no es tan gravoso como la necesidad de él, y el daño deriva casi siempre de la escasa disposición a admitir uno pequeño. Puede objetarse aquí que la condición de los súbditos es muy miserable, puesto que están sujetos a los caprichos y otras irregulares pasiones de aquel o aquellos cuyas manos tienen tan ilimitado poder. [...] En realidad, el poder, en todas sus formas, si es bastante perfecto para protegerlos, es el mismo. Considérese que la condición del hombre nunca puede verse libre de una u otra incomodidad, y que lo más grande que en cualquiera forma de gobierno puede suceder, posiblemente, al pueblo en general, apenas es sensible si se compara con las miserias y horribles calamidades que acompañan a una guerra civil, o a esa disoluta condición de los hombres desenfrenados, sin sujeción a leyes y a un poder coercitivo que trabe sus manos, apartándoles de la rapiña y de la venganza 65 .

\footnotetext{
64 RÍOS URRUTI, 1915: 152-153.

65 HOBBES, 2011: 76.
} 
En efecto, de acuerdo con estas teorías antropológicas pesimistas que definen al hombre como un ser despiadado, egoísta y temible, el miedo constituye la principal motivación primaria para la organización social, y, por esta razón, cobra todo su sentido la implantación de un Estado concebido como una institución coactiva nacida precisamente de ese temor, que esté destinada a reprimir esas fuerzas destructoras del hombre. Se trata pues de instaurar un modelo político donde la coacción constituya un elemento esencial del Derecho. Por esta razón, Ahrens - siguiendo en este aspecto dicha tradición de pensamiento-, da una definición del Estado entendido como una institución protectora y fundamentalmente coactiva.

Ahora bien, la dificultad que plantea Giner a esta doctrina es la siguiente: si partimos de esta definición pesimista del hombre, de su «natura corrupta», entonces, ¿cómo vamos a ser capaces de fundamentar el orden jurídico? De la constatación de que los hombres son violentos, peligrosos y egoístas es fácil deducir la necesidad de un orden de Derecho coactivo, pero no podemos deducir de ahí qué contenido, qué principios o qué estructura axiológica debe tener ese Derecho para garantizar la vida humana en común. El Estado de Ahrens - y más radicalmente el descrito por Hobbes—, se reduciría a un mero orden formal y coactivo, donde el contenido de ese mismo orden estatal sería de carácter contingente o, como él mismo lo expresa, «relativo o condicional», al no ser capaz de encontrar esos principios jurídicos materiales de convivencia dotados de verdadera validez general, y que, en efecto, no son susceptibles de poder derivarse de una definición puramente negativa de la naturaleza humana.

Aquí radicaría el defecto capital de esta argumentación de Ahrens, siguiendo en ello a las corrientes voluntaristas y positivistas; tal sería el talón de Aquiles de su doctrina, en que incidiría la certera crítica de Giner a la definición ahrensiana del Derecho como un orden coactivo exterior. La doctrina de Ahrens sólo acierta pues a probar la necesidad de un orden que asegure la existencia, pero adolece — como muy bien señala Giner-, de todos los principios para la determinación, concreta y justa de este orden. Con otras palabras, Ahrens no nos dice nada sobre cómo garantizar la coexistencia entre individuos a través de ciertos principios éticos materiales, pues de su definición pesimista de la naturaleza humana no se puede derivar sino la necesidad de un orden coactivo, nada más.

4. Una cuarta enmienda a Ahrens, que nos ayuda a concretar y definir mejor la no siempre fácil de concertar posición de Giner en la filosofía jurídica de su tiempo, se dirige a la falta de una distinción clara de la ciencia y el arte en el ámbito de la Política.

En ocasiones — pone de manifiesto Francisco Giner-, Ahrens usa de manera imprecisa el término «político», al no distinguir convenientemente entre 
la ciencia y el arte de la Política, y conformarse con su aplicación al Estado en ambos sentidos sin indicar a qué orden de la política, histórico o filosófico, se está refiriendo ${ }^{66}$. Por ejemplo, tal uso impreciso puede verse en la siguiente afirmación de Ahrens, en la que expresa que

La historia debe, pues, inspirar también en la política una conducta verdaderamente histórica, y prevenir por consiguiente todo proceder y obra artificial que no concierte con las relaciones y necesidades de los tiempos. La política es una ciencia y un arte de lo que en determinadas condiciones es posible y, relativamente, lo mejor. Lo que Sócrates decía de la filosofía vale también de la política: es un arte que no crea de por sí cosa alguna, sino que ayuda a venir al mundo de la existencia exterior al fruto de un germen anterior y sustantivo, una vez llegado a la madurez en las entrañas de la vida ${ }^{67}$.

Giner aclara que el uso que hace aquí Ahrens del término 'política' conduce a una confusión, por lo demás bastante frecuente, entre su ciencia y su arte, y que Ahrens debería haber expresado más claramente en el citado párrafo que, con el término política, se estaba refiriendo a su parte «filosóficohistórica». Según el jurista español, pueden distinguirse, siguiendo su propia arquitectónica krausista del Derecho (vid. supra), al menos tres partes en la Política. La exposición y definición de estas tres versiones de la disciplina política, nos proporciona claves teóricas útiles, no sólo para precisar el sentido en que debe entenderse el texto de Ahrens, además nos procura unos provechosos recursos para matizar el propio pensamiento de Francisco Giner, por ello vamos a repasarlas brevemente a fin de poder concretar en qué consiste esta enmienda a Ahrens.

Para Giner, la política, «como ciencia», es entendida como la ciencia del Estado y, por tanto, abraza al Estado bajo cuantos modos y aspectos puede ser objeto de conocimiento. De ahí que sea necesario distinguir entre una filosofía política, una historia política y una ciencia filosófico-histórica del Estado. De acuerdo con esta concepción tripartir de la Política, estaría, por un lado, $1 .^{\circ} \mathrm{La}$ «filosofía política», que es entendida como una ciencia «filosófica» del Estado, que considera a esta institución en lo esencial y eterno de su naturaleza (en su «idea»), y por consiguiente, en lo que necesariamente «debe ser cada Estado determinado y particular, como tal (el «ideal» del Estado), sobre lo diferencial y característico que lo distingue entre todos. $2 .^{\circ}$ Se precisa también, por otro lado, la existencia de una «historia política», una ciencia «histórica» del Estado, cuyo objetivo es el desarrollo vario y temporal del Estado, en sus hechos, ofreciendo el cuadro de su situación en cada época. $3 .^{\circ} \mathrm{Y}$, en

66 Nota de Giner en: AHRENS, 1878-1880: 200.

67 AHRENS, 1878-1880: 305. 
tercer lugar, es menester una ciencia «filosófico-histórica» del Estado, que, apoyada en las dos anteriores, aplique los principios (el «ideal») de esta institución a sus hechos, los juzgue según aquellos, e indique, en vista del ideal y de las condiciones presentes, con qué progresos inmediatos nos toca contribuir por nuestra parte, en cada época, a la realización proporcionada y gradual de aquella idea que la ciencia señala. Por esta razón, establece Giner que la función del gobierno, de los partidos y del hombre político en general, sólo puede cobrar sentido en este tercer plano filosófico-histórico, por cuanto su acción se da en la transición e individual efectuación del ideal del Estado, de los principios y reglas de conducta cuya observancia hace efectivo el Derecho en el medio de las relaciones históricas de su tiempo.

Y únicamente en este sentido, a saber, en cuanto aquel ideal absoluto sólo a través del ideal propio de cada época determinada puede realizarse y tomar cuerpo en ésta, es el arte político, bajo de ser absoluto, y por serlo, arte relativo también de conseguir lo posible en aquel momento, lo mejor entonces: carácter aplicable asimismo a la ciencia política, pero no a toda ella, sino a su parte filosóficohistórica ${ }^{68}$.

De acuerdo con la distinción que establece Giner en tres niveles, y a la síntesis que se produce en un tercer momento en el que el ideal y la historia quedan inextricablemente unidos, puede comprenderse por qué decíamos que la vindicación krausista de una política con pretensiones de universalidad -coherente con el Ideal para la Humanidad de Krause-, no significaba recaer en un orden de principios metafísicos, ahistóricos e inmutables. Frente a otras versiones dogmáticas u otras concepciones utópicas de una sociedad ideal, encontramos en el krausismo un iusnaturalismo crítico, que parte de la propia función histórica del derecho natural, es decir, de su contribución a fomentar y difundir en la vida social los ideales de la racionalidad y de la emancipación. Por esta razón, creemos que en la filosofía jurídica gineriana sería mejor hablar, no tanto de utopía como de eutopía, pues los krausistas confiaron siempre en el carácter realizable del Ideal de la Humanidad y en el papel que su filosofía jurídica y sociológica tendría en la reforma social y cultural de España.

\section{CONSIDERACIONES FINALES}

En resumen, y a modo de recapitulación, las obras de los discípulos de Krause no se limitan pues a desarrollar aspectos parciales presentes en la se-

68 Nota de Giner en: AHRENS, 1878-1880: 305-306. 
vera indagación filosófica del Derecho Natural de Krause, sino que difiriendo de sus consideraciones en algunos casos, lograron aportar enmiendas y adendas que enriquecieron su doctrina. En cierto modo, puede afirmarse que la obra de Krause se vio completada con la de sus discípulos más directos, cuyos escritos contribuyeron a la divulgación e influjo de las ideas despertadas por el maestro alemán en todas las escuelas jurídicas y políticas de España.

En particular, como se ha podido esclarecer en las cuatro revisiones que el maestro español dirige al jurisconsulto alemán, hemos visto cómo Giner encuentra borrosa la línea que el discípulo aventajado de Krause, Heinrich Ahrens, traza entre el derecho y la moral en su Enciclopedia Jurídica. Por esta razón, según hemos podido analizar, sus comentarios están destinados a corregir esta falta de precisión en determinados conceptos jurídicos que, en algunos casos, hacían ambiguo e inconsistente el discurso de Ahrens. La vaguedad de su razonamiento reside — según Giner-, en que, por un lado, este autor defiende que el Derecho es una relación social y que se halla sometido a la autoridad de los poderes públicos del Estado, pero, por otro lado, su concepto del Derecho conservaría ese carácter espiritual y ético que, siguiendo el dictamen krausista, trata de sustentar Ahrens ${ }^{69}$. Las ideas jurídicas de Ahrens oscilan, por tanto, entre la doctrina corriente de la exterioridad del Derecho, determinado bajo la acción sancionadora de los poderes públicos y de su poder coercitivo y, por otro lado, entre la concepción krausista -incompatible con esta doctrina-, del «carácter ético» que el autor mismo atribuye al Derecho todo, como un orden primera y fundamentalmente interior.

La manera como Ahrens hubiera evitado la vaguedad citada, si seguimos las ideas esenciales que ostenta la exposición gineriana acerca de la verdadera distinción entre derecho y moral —que no equivale a la usual de los actos en morales y jurídicos, toda vez que «unos mismos actos» son morales, en un respecto, y jurídicos, en otro-, sería considerando al Derecho como una relación interna, tan individual como social, reconociendo en él su valor ético; y también limitando la acción del Estado (social-público) a un círculo «particular» en el orden entero jurídico social, puesto que — de acuerdo con la filosofía jurídica krausista española en la obra tanto de Francisco Giner como de Adolfo Posada, entre otros - , la esfera de los poderes públicos no coincide con la del derecho, sino que le es interior y de menor radio. Así pues, para los krausistas españoles, al contrario que los liberales clásicos, no hacen de lo público y lo privado dos espacios divididos y excluyentes, sino que dan una amplísima definición de la soberanía que invade todos los campos, planteando que el poder no se ejerce sólo de forma descendiente - como viene expuesto por los liberales individualistas con su división de los órdenes inter-

\footnotetext{
69 AHRENS, 1878-1880: 56.
} 
no/externo y su doctrina del Estado-, si no también de forma ascendiente y horizontal, es decir de lo privado a lo público. Sobre esta peculiar relación que la filosofía krausista estable entre el Estado (nacional) con los otros Estados intermedios sociales (las «personas sociales totales» y «especiales») y el «Estado individual» que Giner reconoce en la esfera de conciencia de cada individuo y que también es Derecho, radica una de las más interesantes aportaciones de la doctrina gineriana al concepto del Derecho, que supuso todo una revisión de los postulados ahrensianos, como es la distinción gineriana entre sociedad y Estado que ha encontrado una importancia capital y ha asentado algunos principios básicos de sociología y la filosofía jurídica moderna.

En este sentido, quizá no le falte razón a la opinión que estima en este punto que Giner es «un gran maestro que humildemente se cobija en una cabaña ajena, teniendo solar y materiales de construcción para edificar casa propia» ${ }^{70}$. Este cobijo que le procuró en la fase inicial de su pensamiento la doctrina filosófica-jurídica de Krause, y cuya base ética puede constatarse en sus Principios de Derecho Natural ${ }^{71}$, le dotó luego de los medios necesarios para emanciparse de algunos postulados de Ahrens y desarrollar su obra más madura y genuina: mantener con rigor, por un lado, las exigencias ideales de la Moral para el progreso de la justicia y el Derecho y, por otro, estimar la vida real cumplidamente y la legitimidad que recibe de la historia y las costumbres.

\section{BibLIOGRAFÍA}

Ahrens, Heinrich, Enciclopedia Jurídica o Exposición orgánica de la ciencia del derecho y del estado, versión directa del Alemán, con notas críticas y un estudio sobre la vida y obras del autor por Francisco Giner, Gumersindo de Azcárate y Augusto G. Linares, 3 tomos, Madrid, Victoriano Suárez, 1878-1880.

Ahrens, Heinrich, Compendio de la historia del derecho romano, versión directa del alemán, con notas críticas por F. Giner, G. de Azcárate y A. G. de Linares, Madrid, Librería de Victoriano Suárez, 1879.

Alas, Leopoldo (Clarín), «El derecho y la moralidad», Revista Europea, XII/240 (Madrid, 1878): 260-267, 292-297, 326-330, 360-364, 399-403, 427-443, 461466, 487-495 y 532-527.

Álvarez Lázaro, Pedro. F. y Menéndez Ureña, Enrique (eds. lits.), La actualidad del krausismo en su contexto europeo, Madrid, Editorial Parteluz/Fundación Duques de Soria/ Universidad Pontificia Comillas, 1999. Colección del Instituto de Investigación sobre Liberalismo, Krausismo y Masonería, 16.

Atienza, Manuel, El sentido del Derecho, Barcelona, Editorial Ariel, 2003.

70 CABALLERO, XLVI/I (Madrid, 1922): 92.

71 GINER, 1916. 
Caballero Rodríguez, Juan, «Los Estudios jurídicos y políticos de Francisco Giner de los Ríos», Boletín de la Institución Libre de Enseñanza (BILE), XLVI/I (Madrid, 1922): 92-95.

Costa Martínez, Joaquín, La vida del Derecho, ensayo sobre el derecho consuetudinario, prólogo para esta nueva edición de don José-Luis Lacruz Bermejo, Zaragoza, Guara editorial, 1982. (1 ${ }^{\mathrm{a}}$. ed. 1876).

Díaz, Elías, La filosofía social del krausismo español, Madrid, Editorial Cuadernos para el diálogo, 1973.

Díaz, Elías, Sociología y Filosofía del Derecho, Madrid, Taurus Ediciones, 1976.

Giner de los Ríos, Francisco, «El principio ético en el derecho privado», BILE, II/II (Madrid, 1878a): 144-145.

Giner de los Ríos, Francisco, «Sobre lo moral y lo jurídico», BILE, II/II (Madrid, 1878b): 175 .

Giner de los Ríos, Francisco y Azcárate, Gumersindo de, Notas a la Enciclopedia Jurídica de Enrique Ahrens. Con una nota sobre Arrendamientos rurales y pecuarios de Joaquín Costa. Prólogo de Pablo de Azcárate, vol. XXI, Madrid, OO. CC., 1965.

Giner de los Ríos, Francisco y Calderón, Alfredo, Prolegómenos del derecho. Principios de derecho natural, vol. I, Madrid, OO.CC., 1916.

Giner de los Ríos, Francisco y Calderón, Alfredo, Resumen de Filosofía del Derecho, vol. I, Madrid, OO.CC., 1926.

Hart, Herbert Lionel Adolphus, El Concepto de Derecho, traducción de Genaro R. Carrió, Buenos Aires, Abeledo-Perrot, 1977.

Hobbes, Thomas, Leviathan, México, D.F., INEP AC, 2011. Biblioteca del Político, XVIII.

Krause, Karl Christian Friedrich, Ideal de la Humanidad para la Vida, con introducción y comentarios por D. Julián Sanz del Río, Catedrático de Historia de la Filosofía en la Universidad Central, Madrid, Imprenta de Manuel Galiano, 1860 (Madrid, Imprenta de F. Martínez García 1871; Madrid, Biblioteca Económica Filosófica, 1904; Barcelona, Ediciones Orbis, 1985).

Manzanero, Delia, «Francisco Giner y Adolfo Posada, precursores de la Sociedad de Naciones», Pensamiento. Revista de investigación e información filosófica, 265/71 (Madrid, 2015a): 53-71. doi: pen.v70.i265.y2015.003.

Manzanero, Delia, «La Epiqueya en la obra de Francisco Giner: una vía intermedia entre iusnaturalismo e historicismo», Revista de Hispanismo Filosófico, 20 (Madrid, 2015b): 47-62.

Menéndez Pelayo, Marcelino, «II - El krausismo. -Don Julián Sanz del Río; su viaje científico a Alemania; su doctrina; sus escritos hasta 1868; sus principales discípulos»), en Historia de los Heterodoxos Españoles, Alicante, Biblioteca Virtual Miguel de Cervantes, 2003. Edición digital basada en la de Madrid, La Editorial Católica, 1978. $1^{\mathrm{a}}$ ed. Madrid, 1880-1882.

Menéndez Ureña, Enrique, «El fraude de Sanz del Río o la verdad sobre su Ideal de la Humanidad», Pensamiento. Revista de investigación e información filosófica, 44/173 (Madrid, 1988): 25-48. 
Menéndez Ureña, Enrique, Krause, educador de la humanidad. Una biografía, Madrid, Universidad Comillas/Unión Editorial, 1991.

Menéndez Ureña, Enrique, Cincuenta cartas inéditas entre Sanz del Río y krausistas alemanes (1844-1869), Madrid, Publicaciones de la Universidad Pontificia Comillas, 1993. Colección LKM, 6

Menéndez Ureña, Enrique, Fernández, J. L. y Seidel, J., El 'Ideal de la Humanidad' de Sanz del Río y su original alemán. Textos comparados con una Introducción, Madrid, Publicaciones de la Universidad Pontificia Comillas, 1992. Colección LKM, 4.

Menéndez Ureña, Enrique y Vázquez-Romero, José Manuel, Giner de los Ríos y los krausistas alemanes correspondencia inédita. Con introducción, nota e índices. Presentación de José Manuel Pérez-Prendes Muñoz-Arraco, Madrid, Universidad Complutense de Madrid, 2003.

Payo de Lucas, Jesús, La antropología de Francisco Giner. En busca de la libertad democrática, Madrid, Editorial Dykinson, 2012.

Querol Fernández, Francisco, La filosofía del derecho de K.Ch.F. Krause. Con un apéndice sobre su proyecto europeísta, Madrid, Universidad Comillas/Unión Editorial, 2000.

Ramos Pascua, José Antonio, La ética interna del Derecho. Democracia, Derechos Humanos y principios de justicia, Bilbao, Editorial Desclée de Brouwer, 2007.

Ríos Urruti, Fernando de los, «Ensayo sobre la Filosofía del Derecho en D. Francisco Giner y su relación con el pensamiento contemporáneo», BILE, XXXIX/I (Madrid, 1915): 145-160.

Ríos Urruti, Fernando de los, La Filosofía del Derecho en Don Francisco Giner y su relación con el pensamiento contemporáneo, Madrid, Biblioteca Corona, 1916.

Sanz del Río, Julián, «El Derecho como idea fundamental en la vida», BILE, VI/I (Madrid, 1882a): 41-42.

Sanz del Río, Julián, «El Derecho y el Estado, según Krause», BILE, VI/II (Madrid, 1882b): 197-198, 209-211 y 269-270.

Vázquez-Romero, José Manuel, «Una revisión del panorama krausológico actual», Notas. Reseñas iberoamericanas. Literatura, sociedad, historia, 16/1 (Madrid, 1999): 2-14.

Vázquez-Romero, José Manuel, «La micrópolis del yo. Representación, soberana e individuo en los escritos de Francisco Giner de los Ríos», Pensamiento. Revista de investigación e Información filosófica, 63/236 (Madrid, 2007): 199-234.

Vázquez-Romero, José Manuel, «Dos en uno. El concepto de Estado individual krausista y su relevancia biopolítica», en Francisco Giner de los Ríos (ed.), Actualidad de un pensador krausista, Madrid, Marcial Pons/Ediciones de Historia, 2009.

Recibido: $25 / 06 / 2015$

Aprobado: 21/10/2016 